\title{
Syntactic Complexity in Secondary-level English Writing: Differences Among Writers Enrolled on Bilingual and Non-bilingual Programmes
}

\author{
Ana Cristina Lahuerta Martínez \\ Universidad de Oviedo
}

Received: 29 June 2016 / Accepted: 14 October 2016

ISSN: $1697-7467$

\begin{abstract}
This study examines syntactic complexity in the writings of secondary education students from bilingual and non-bilingual contexts. The participants were $393 \mathrm{stu}-$ dents in their third and fourth year of compulsory secondary education. Essays were evaluated by a selection of measures gauging complexification at the sentential, the clausal, and the phrasal level of syntactic organisation. Findings showed significant differences between the bilingual and the non-bilingual groups with the scores on all syntactic complexity measures being significantly higher in the bilingual programme group. The comparison between grades in both groups suggested a significant increase in clausal coordination and phrasal elaboration in both groups but no significant difference in subordination in the bilingual group pointing to a possible interplay of coordination and subordination according to the programme selected.
\end{abstract}

Keywords: writing, syntactic complexity, secondary education, bilingual programmes.

Estudio de la complejidad sintáctica en las composiciones en inglés de estudiantes de educación secundaria: Diferencias entre estudiantes de programas bilingües y no bilingües.

RESUMEN: Este estudio examina la complejidad sintáctica en las composiciones de estudiantes de educación secundaria de un programa bilingüe y otro no bilingüe. Los participantes eran 393 alumnos de tercer y cuarto curso de educación secundaria obligatoria. Se analizaron las composiciones de los participantes mediante medidas de complejidad sintáctica en los niveles de oración, cláusula y frase. Los resultados muestran que los estudiantes del grupo bilingüe obtienen significativamente mejores resultados en todas las medidas de complejidad sintáctica. La comparación entre niveles en ambos grupos muestra un aumento significativo en la coordinación y la elaboración a nivel de la frase en ambos grupos pero no una diferencia significativa en subordinación en el grupo bilingüe lo que parece indicar una posible interacción entre coordinación y subordinación según el programa seleccionado.

Palabras clave: escritura, complejidad sintáctica, educación secundaria, programas bilingües.

\section{INTRODUCTION}

Complexity has emerged as a major dimension to assess and investigate L2 writing performance and development (Wolfe-Quintero, Inagaki and Kim, 1998). In L2 research, 
as in L1 research, "complexity has been proposed as a valid and basic descriptor of L2 performance, as an indicator of proficiency and as an index of language development and progress" (Bulté and Housen, 2014:43).

Linguistic complexity, the focus of the present study, has been characterized as "the extent to which language produced in performing a task is elaborate and varied" (Ellis, 2003:140). It can be investigated "at the level of the language system as a whole (or of its major subsystems) and at the level of the individual linguistic features that make up such (sub-)systems. All these different types, components and subdimensions of complexity can be studied across various domains of language such as the lexicon, syntax, and morphology" (Bulté and Housen, 2014: 44). The present study focuses exclusively on syntactic complexity, understood broadly, as "the range and the sophistication of grammatical resources exhibited in language production" (Ortega, 2015: 82).

This study examines syntactic complexity in the writings of students at different levels of proficiency and who belong to different instructional settings. The present paper compares the writing of third and fourth year secondary education students enrolled on a bilingual and a non-bilingual programme. Bilingual programmes or the content and language integrated learning (CLIL) approach as it is also known in Europe and other parts of the world, is considered to be an alternative path to conventional English as a Foreign Language Teaching (Gené et al., 2015). Bilingual programmes are believed to promote learning since they focus on meaning and communication, and as a result improve overall language competence in the target language (Lasagabaster, 2008; Heras and Lasagabaster, 2015). Bilingual classrooms are "acquisition-rich environments in which learners are necessarily engaged in the manipulation of complex language" (Lorenzo and Rodríguez, 2014:65).

Within this framework, this paper focuses on the role of writing in bilingual contexts, an area that has received very little attention within bilingual or CLIL studies (Gené et al., 2015). It focuses on language proficiency here operationalised as complex syntax and it explores the development of written language competence, when a foreign language is used as a vehicle of communication in formal bilingual contexts as compared to non-bilingual contexts. The scarce literature existing on written syntactic complexity in bilingual contexts is far from conclusive. Hence, the present study intends to make a contribution in this direction.

\section{A review of the literature}

Some recent cross-sectional studies have examined the extent to which different syntactic complexity measures accurately are evidence of L2 writers' global proficiency (e.g. Ai and Lu, 2013; Ji-young Kim, 2014), or writing quality (e.g. Taguchi et al., 2013). Ai and $\mathrm{Lu}$ (2013) reported differences in several dimensions of syntactic complexity between the argumentative writing of non-native students at both low and high proficiency levels and that of native students, including length of production unit, amount of subordination and coordination, and degree of phrasal sophistication. Ji-Young Kim (2014) investigated whether second language writings at different proficiency levels could be distinguished using automatic indices of linguistic complexity. Results showed that more proficient writers produced longer texts, used more diverse vocabulary, and showed the ability to write more 
words per sentence and more complex nominalizations. In a study designed to identify linguistic features that distinguished essays of different quality, Taguchi et al. (2013) analysed a collection of argumentative essays written by non-native speakers of English. A measure of syntactic complexity, noun phrase modification contributed to essay quality.

Longitudinal studies carried out to track and compare learner development in syntactic complexity over time are also to be found in the literature (e.g., Bulté and House, 2014; Knoch, Rouhshad, and Storch, 2014; Knoch, Rouhshad, Oon, and Storch, 2015). Bulté and Housen (2014:42) examined the extent of the development of English L2 writing proficiency of adult ESL learners over the time of an intensive short-term academic English language programme. They used quantitative measures targeting different components of syntactic complexity at the sentential, the clausal, and the phrasal level of syntactic organization. Results showed that the scores on all syntactic complexity measures increased and for all but three sentential complexity measures (complex sentence ratio, compound-complex sentence ratio, and subclause ratio) the increase was statistically significant. Results pointed to a significant increase in both clausal coordination and phrasal elaboration, but not in subordination. Knoch et al., (2014: 8-10) and Knoch, et al., (2015: 50) found significant writing development in students who had spent some period of study abroad but limited to their fluency (measured via text length). That is, they could write longer texts in the time allowed but there were no observed gains in syntactic complexity.

Godfrey, Treacy, and Tarone (2014) also reported longitudinal studies, but comparing the performance of different groups. They examined the writing of eight university learners of French-four during study abroad and four in on-campus courses- over the period of a semester. A clause/T-unit analysis showed that both groups increased the syntactic complexity in their writing, although the domestic group improved more than the study abroad group did.

Researchers have also found that syntactic complexity in L2 writing may be affected by various factors, such as topic (e.g. Yang et al., 2015), genre (e.g. Mazgutova and Kozrmos, 2015), and instructional setting (e.g., Gené-Gil et al. 2015; Lasagabaster, 2008; Lorenzo and Rodríguez, 2014; Navés and Victori, 2010). Owing to space limitations and the focus of the present study, we will concentrate on the studies that examine the effect of instructional setting.

Research on the benefits of bilingual contexts on written development is inconclusive. Some studies suggest the existence of limited progress regarding writing in CLIL classrooms. Thus, Llinares and Whittaker's (2006) data revealed that their secondary Spanish CLIL participants' compositions learning social science through English attained some of the subject-specific features of their discipline (e.g. the distribution of the most common words in their compositions), while some other resources, such as modality or clause expansion through elaboration, were hardly ever used in their compositions.

Some other studies have shown benefits in writing. Thus, taking on a holistic perspective, Lasagabaster (2008) examined foreign language written competence in CLIL contexts. The sample used included a group made up of non-CLIL students in the fourth year of secondary education, another group made of CLIL students in the fourth year of secondary education and a third group made up of CLIL students in the third year of secondary education. He found significant outperformance in favour of CLIL students in overall written production and in most of the measures analysed. His findings were in line with those of Roquet (2011) who found that the formal instruction (FI)+CLIL group consistently tended to write a better organised, more accurate, lexically richer and more purposeful composition 
than the formal instruction group, and Navés (2011) who found greater benefits for CLIL secondary students in overall writing. Using analytical complexity measures, Navés and Victori (2010) carried out two studies produced in a CLIL environment with CLIL and non-CLIL learners from two primary and three secondary schools. Results (2010:41-43) showed that CLIL learners' writing as measured by subordinate clauses at lower grades was observed to be as good as or even better than that of older learners a few grades ahead. Lorenzo and Rodríguez (2014: 64) approached the appearance and evolution of academic written language structures in a second language, in formal bilingual contexts. The authors analysed a corpus of historical narratives of subjects from the third year of secondary education to the second year of post-compulsory secondary education (baccalaureate). The study employed complexity measures, among them the mean length of sentential units, dependent clauses per clause, coordinate phrases per clause, complex nominals per T-unit, and complex nominals per clause. Results (2014: 68-70) showed that learners in the lowest grades produced an amalgamated language, characterized by a lack of dependent clauses, and coordinate phrases. However, this language skill was consolidated in higher grades, where everything was more syntactically complex. The data showed significant advances in mean length of clause, dependent clause per clause or sentence subordination, as well as complex nominals per clause (2014:70). This positive outcome about CLIL is shared by Gené-Gil et al. (2015) who carried out a longitudinal study on the development of written complexity, accuracy and fluency in secondary education CLIL and non-CLIL learners. Within-group results showed significant differences in the scores obtained in most of the measures used, including the two complexity measures used, namely coordination index and subordination ratio, for CLIL learners at the different data collection times, compared to significant differences only in lexical complexity and accuracy for non-CLIL participants.

The studies reviewed have shown that L2 learners' scores on complexity measures increase over time or as general L2 proficiency develops. With respect to the number of studies that specifically compare bilingual and non-bilingual contexts, there are some discrepancies in their findings on writing development, which may have arisen because of the approach as well as the analytical method used by each one of them. Thus, some studies employ a holistic perspective (Lasagabaster, 2008; Roquet, 201; Navés, 2011). There are also studies that approach writing from the acquisition of the register features of a discipline (Whitaker and LLinares, 2006; Lorenzo and Rodríguez, 2014). Finally, there are studies that adopt an analytical approach although they use a variety of measures to gauge syntactic complexity.

\section{The PRESENT STUdY}

The current study will try to solve and clarify the above discrepancies by using a set of complexity measures that reflect different underlying constructs: sentential, clausal, and phrasal complexity, something lacking in the literature (Bulté and Housen, 2014). As a result, in comparison with a lot of previous studies, which target either the phrasal and clausal level of syntactic organization or the sentence level, we use a multidimensional construct of complexity in order to get a comprehensive picture of L2 writing development. This may ultimately allow us to identify which different areas of complexity may be more or less relevant at different given proficiency levels. Moreover, we will use a large participant pool 
as it is rare in L2 research to have experimental groups of 100 participants each.

The goal of the current study is to examine differences in the syntactic complexity in English writing among secondary-level writers with different teaching programmes and considering grade in the analysis.

The following research questions are the focus of the study:

Research Question 1: Is there a significant difference in syntactic complexity between the bilingual and the non-bilingual groups?

Research Question 2: Is there a significant difference in syntactic complexity between the third and fourth year groups?

Research Question 3: is there a significant correlation between syntactic complexity measures and holistic ratings?

\section{4. Мethod}

\subsection{Measures}

The essays were evaluated by means of both subjective ratings of writing quality as well as by a selection of quantitative measures gauging different aspects of L2 complexity calculated by the present author. Following Bulté and Housen (2014), the final subjective rating score was a combination of rating on four scales: Content; Organization; Language Use; Vocabulary and Mechanics (see Bulté and Housen: 2014: 47).

Norris and Ortega (2009) propose examining syntactic complexity as a multi-dimensional construct. They recommend that researchers should at least incorporate measures for global or general complexity, complexity by subordination, complexity via phrasal elaboration, and possibly coordination. Recent studies insist on the need for a sufficiently wide range of carefully chosen complexity measures in order to get a comprehensive picture of L2 complexity development, given its multidimensional, multilayered, and non-linear nature (Bulté and Houlsen, 2014; Yang et al,. 2015: Lu and Ai, 2015).

The present study follows these recommendations and the syntactic complexity measures were chosen to gauge complexification at the sentential, the clausal, and the phrasal level of syntactic organisation. Following three groups of measures gauging sentential syntactic complexity were selected, "each capturing a different but interrelated aspect of sentence complexity" Bulté and Housen (2014: 47). The first set examined sentence complexity in terms of the mean length of sentential unit in words: mean length of sentence. The second set focused on sentence composition in terms of clauses and included four measures: the simple sentence ratio, compound sentence ratio, complex sentence ratio, and the compound-complex sentence ratio, that is, the proportion of each type of sentence with respect to the total number of sentence types in the composition. The third set of measures examined proposition combining and clause linking: the coordinate clause ratio and dependent clause ratio. We also calculated syntactic complexity at the phrasal level using mean length of noun phrase. Finally, we included an overall sentence complexity measure (clauses per sentence).

All essays were analysed by two researchers and all disagreements were discussed until 
agreement was reached. For the purpose of this study, we followed Verspoor and Sauter (2000: 33-42) and defined a clause as a unit consisting of a subject (explicit or implied) and a predicate. Dependent clauses comprise adverbial clauses, complement clauses, and relative clauses. With respect to the four types of sentences, they are defined as follows: A simple sentence consists of one main clause only. A compound sentence consists of two or more main clauses and the clauses are independent and may stand on their own. A complex sentence is a sentence that contains at least one full dependent clause with its own subject and predicate. A dependent clause is a clause that starts with a subordinator, a word like because, although, if, who and so on. Compound-complex sentences are sentences that have a compound sentence with complex parts, or a complex sentence with compound parts.

\subsection{Participants}

In this study, we hope to circumvent the limitations of previous studies by using a large sample size, as recommended in the literature (e.g., Yang et al., 2015). The participants were 393 secondary education students who had started learning English at the age of five. The sample was divided into four groups: Two groups of students enrolled on a bilingual programme, consisting of a first group made up of 101 students in the third year of compulsory education and a second group made up of 104 students in the fourth year of compulsory education. Two groups of students who did not follow a bilingual program, which consisted of a group of 98 students in the third year of compulsory education, and a group of 90 students in the fourth year of compulsory education. Of the total of students, 195 were men and 198 women. Third year bilingual and non-bilingual students' average age was 14 years and fourth year bilingual and non-bilingual students' average age was 15 years. Participation in the bilingual programme was optional. Students join the programmes on a voluntary basis and no selection criteria are prescribed by the schools.

\subsection{Context}

This study was conducted in seven state-run high schools in the north of Spain. In those schools, English was taught as a foreign language. The CLIL programme was first implemented in the academic year 2004-2005 in both primary and secondary education in Asturias and has grown exponentially since then. Schools joined the programme on a voluntary basis and they could choose the subjects and the levels involved, provided they had content teachers with the minimum language qualifications required (B2 of the Common European Framework of Reference for Languages) and fulfilled all legal regulations. The teachers participating were encouraged to attend CLIL training courses.

The students enrolled on bilingual programmes have two and a half hours a week of English in the first and second year of primary education and three hours a week from third to sixth year. They also have two hours a week of a content subject taught in English being arts and science the most common choices in primary education. In secondary education, they have five hours of English a week from first to fourth year. In addition, they also have three hours a week of a content subject taught through English. In secondary education, the 
content subject taught through English can be any subject of the curriculum of the corresponding year imparted in the school. The most common choices are nevertheless geography and history, technology, biology and geology.

On the other hand, those students enrolled on non-bilingual programs have two hours a week of English in the first and second year of primary education, two and a half in third and fourth year and three hours a week from fifth to sixth. They have four hours of English a week from first to third year of compulsory secondary education and three hours in fourth year of compulsory secondary education. (BOPA num.21, 27/05/2009).

Regarding the methodology used by the two instruction programmes, students in the bilingual setting receive writing instruction and writing assignments in their content subject classes in addition to their English classes.

\subsection{Procedure}

For the present study, the data come from a written composition activity, which was administered to participants in their own classroom. For the written activity, students had to write on the topic 'Do you think school uniform should be worn at the high school?' All the participants were given 30 minutes for the writing activity. In this way, both time and topic constraints were controlled in order to make results comparable (Wolfe-Quintero et al. 1998).

\section{Results}

Research Question 1: Is there a significant difference in syntactic complexity between the bilingual and the non-bilingual groups?

A statistical analysis was carried out with the program R Development Core Team 2012, 2.15 version. In order to investigate whether any differences existed in the L2 writings of the two groups, we calculated mean scores and standard deviations for the two data collection points, and used paired-samples Student's T tests and Wech's T tests to check for the significance of the differences observed. We regard as statistically significant differences those in which p-value was lower than 0.05 .

Results revealed significant differences between the bilingual and non-bilingual programme groups. Moreover, this difference was significant for all the measures examined. As we can see in Table 1, the bilingual programme group outperformed the non-bilingual programme group in the general quality of the compositions, as well as in all the complexity measures used with the exception of the simple sentence ratio. First, both the sentential length measure and the measure of overall sentence complexity (mean length of sentence and sentence complexity ratio respectively) obtained significantly higher scores in the bilingual programme writings. At the level of sentence composition, bilingual students employed significantly fewer simple sentences at the expense of more compound, complex and compound-complex sentences. The proportion of coordinated and subordinated clauses increased significantly in the bilingual group. Finally, at the phrasal level, the bilingual group obtained a significantly higher score in degree of phrasal complexity. 
Table 1: Bilingual vs non-bilingual programme syntactic complexity

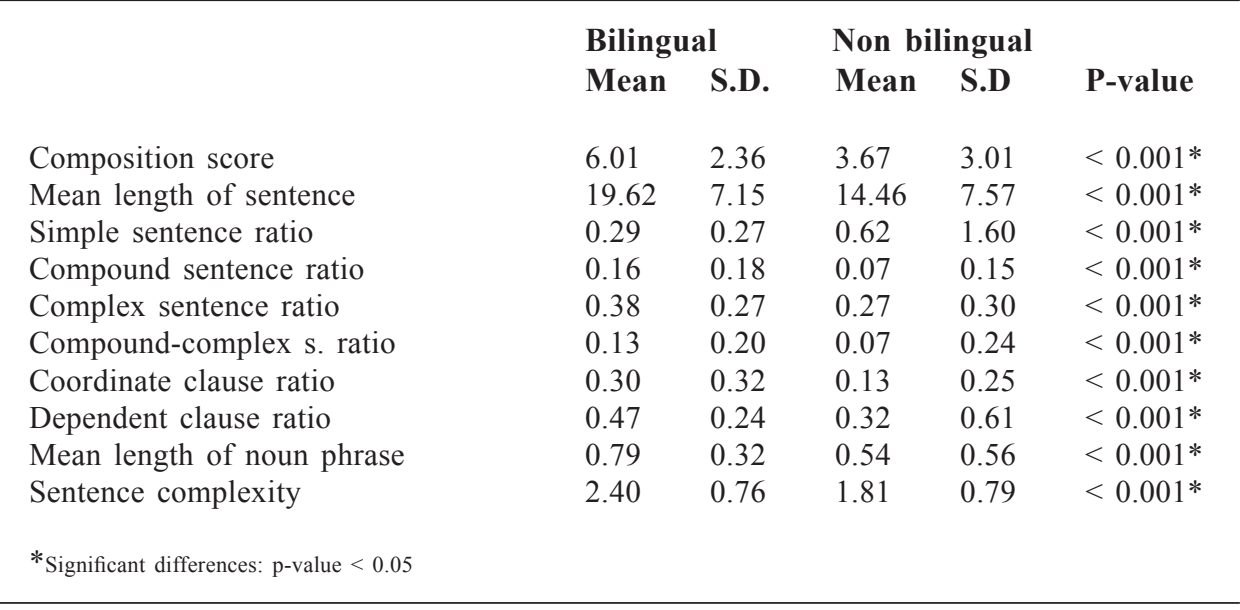

Research Question 2: Is there a significant difference in syntactic complexity between the third and fourth year groups?

When we compared third and fourth year students' writings in the bilingual group we observed that fourth-year students obtained statistically significant higher scores in the general quality of the compositions and in six out of nine sentential complexity measures, among them the overall measure of sentence complexity (sentence complexity ratio). We observed a significant increase in nominalisation, in the proportion of compound, complex and compound-complex sentences as well as in the proportion of coordinated clauses per sentence. Some results contradict our predictions though. Surprisingly, the score on the proportion of dependent clauses per total number of clauses was not significantly higher among fourth year students in the bilingual programme group.

Table 2: Third and fourth year bilingual group syntactic complexity

\begin{tabular}{llllll}
\hline & \multicolumn{3}{l}{ 3th year } & \multicolumn{2}{l}{$\mathbf{4}^{\text {th }}$ year } \\
Mean & S.D. & Mean & S.D. & P-value \\
& & & & & \\
& 5.56 & 1.91 & 6.45 & 2.68 & $<0.001^{*}$ \\
Composition score & 18.67 & 6.67 & 20.53 & 7.41 & 0.06 \\
Mean length of sentence & 0.32 & 0.31 & 0.27 & 0.24 & 0.24 \\
Simple sentence ratio & 0.14 & 0.19 & 0.18 & 0.16 & $<0.05^{*}$ \\
Compound sentence ratio & 0.38 & 0.31 & 0.46 & 0.22 & $<0.05^{*}$ \\
Complex sentence ratio & 0.10 & 0.16 & 0.17 & 0.23 & $<0.05^{*}$ \\
Compound-complex sentence ratio & 0.23 & 0.31 & 0.37 & 0.32 & $<0.001^{*}$ \\
Coordinate clause ratio & 0.37 & 0.16 & 0.37 & 0.16 & 0.22 \\
Dependent clause ratio & 0.65 & 0.28 & 0.81 & 0.34 & $<0.001^{*}$ \\
Mean length of noun phrase & 2.31 & 0.79 & 2.40 & 0.72 & $<0.001^{*}$ \\
Sentence complexity & & & & & \\
* & & & & & \\
\hline
\end{tabular}


When we compared third and fourth year students' writings in the non-bilingual group we found out that fourth year students outscored third year students in the general quality of the compositions and in all the complexity measures (except for simple sentence ratio). This superiority in score was significant for all but two sentential complexity measures (compound-complex sentence ratio, and dependent clause ratio).

Table 3: Third and fourth year non-bilingual group syntactic complexity

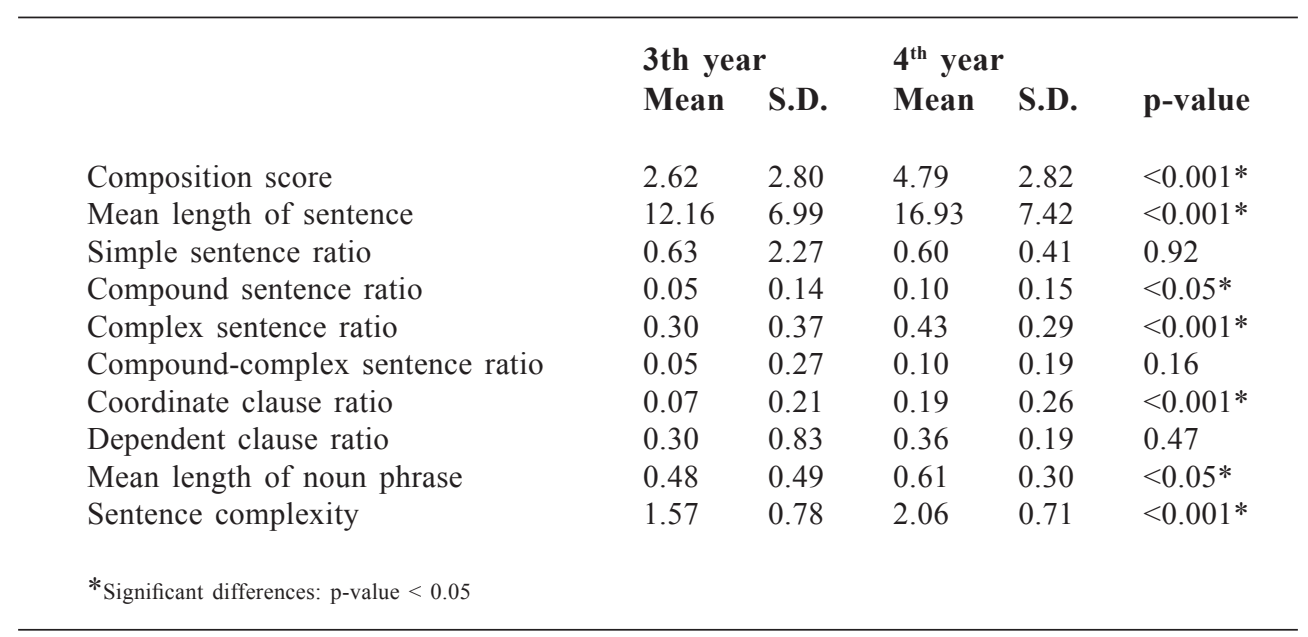

We also compared the bilingual third grade students and the third and fourth grade non-bilingual students. The students enrolled on third grade bilingual programmes scored higher than the non-bilingual fourth graders in the general quality of the compositions as well as in all the other measures with the exception of simple sentence ratio. This difference was significant in the general quality of the compositions (3th Bilingual: Mean $=5.56$, 4th Non-Bilingual, Mean= $4.79 \mathrm{p}$-value $<0.05)$. It also turned out to be significant in four measures: compound sentence ratio (3th Bilingual: Mean $=0.32$, 4th Non-Bilingual, Mean= 0.40 , p-value $<0.05$ ); dependent clause ratio (3th Bilingual: Mean $=0.44$, 4th Non-Bilingual, Mean $=0.36$, p-value $<0.05$ ); mean length of noun phrase (3th Bilingual: Mean $=0.81$, 4th Non-Bilingual, Mean $=0.61$, p-value $<0.01$ ); and sentence complexity (3th Bilingual: Mean=2.31, 4th Non-Bilingual, Mean= 2.06, p-value $<0.05$ ).

Research Question 3: is there a significant correlation between syntactic complexity measures and holistic ratings?

A further aim of this study was to find out how the different measures of writing ability correlated with the global score. Significant strong correlations were observed between the subjective writing quality ratings and all but two of the complexity metrics in both groups. In the bilingual group, the strongest correlations $(<0.001)$ are found for the simple sentence ratio, compound-complex sentence ratio, coordinate clause ratio, noun phrase per clause and sentence complexity. Non-significant correlations characterised the relationships 
between writing quality ratings and dependent clause ratio. In the non-bilingual group, all the significant correlations are strong $(<0.001)$. Non-significant correlations characterised the relationships between writing quality ratings and simple sentence ratio.

Table 4: Correlations between syntactic complexity measures and global score in the bilingual and non-bilingual group

Bilingual group

\begin{tabular}{llcccc}
\hline Mean length of sentence & 0.147 & 0.034 & 0.506 & $<0.001$ \\
Simple sentence ratio & -0.250 & $<0.001$ & -0.017 & 0.809 \\
Compound sentence ratio & 0.146 & 0.037 & 0.291 & $<0.001$ \\
Complex sentence ratio & 0.095 & 0.046 & 0.420 & $<0.001$ \\
Compound-complex sentence ratio & 0.353 & $<0.001$ & 0.219 & 0.001 \\
Coordinate clause ratio & 0.271 & $<0.001$ & 0.378 & $<0.001$ \\
Dependent clause ratio & 0.039 & 0.576 & 0.243 & $<0.001$ \\
Mean length of noun phrase & 0.382 & $<0.001$ & 0.617 & $<0.001$ \\
Sentence complexity & 0.188 & 0.007 & 0.306 & $<0.001$ \\
& & & & & \\
*Significant differences: p-value $<0.05$ & & & & & \\
\hline
\end{tabular}

\section{Discussion}

In this study, we investigated and compared the written competence of a group of students enrolled on a bilingual programme and another group enrolled on a non-bilingual programme. What follows is a discussion of the main results.

Our data revealed that, overall the bilingual approach had a positive effect on the writings of secondary education students. More specifically, in relation to our first research question, which concerned the comparison between the writing in English of bilingual students and their non-bilingual counterparts, our findings showed significant differences between the bilingual and the non-bilingual programme groups with the scores on all syntactic complexity measures being significantly higher in the bilingual programme group. First, bilingual programme students' writings' overall sentence complexity was higher than their non-bilingual counterparts'. The sentences they produced were also significantly longer. The bilingual programme students used more complex noun phrases than the non-bilingual programme students did. They also wrote fewer simple sentences and more compound, complex and compound-complex sentences. Finally, the number of coordinated clauses per sentence and the proportion of subordinated clauses were higher in the bilingual group. We can conclude that there was a significant difference between both groups at all levels of syntactic organization analysed (phrase, clause and sentence).

These findings support the results of previous studies (e.g. Lasagabaster, 2008; Navés, 2011; Roquet, 2011) that found significant outperformance in favour of CLIL students in 
overall written production, and they agree with the works by Navés and Victori (2010) that showed significant outperformance in grammatical complexity of bilingual programme secondary education students. The results are also in line with Gené-Gil et al. (2015) whose findings revealed that CLIL students wrote more syntactically complex texts over time. Our results clearly point to the effectiveness of bilingual settings to develop written competence.

The comparisons between third and fourth year students in each programme group allowed us to identify how syntactic complexity develops within a school setting. We observed that both the bilingual and the non-bilingual programme fourth grade students outperformed third graders in the general quality of the compositions and in most complexity measures of writing used, including overall sentence complexity. The data showed higher scores at higher grades in complex noun phrases or nominals, which agrees with Bulté and Housen (2014), Lorenzo and Rodríguez (2014), Ji-young Kim (2014) and Lu (2011). Nominalization points to increased use of determiners and modifiers of the NP head and as Lorenzo and Rodríguez (2014:68) state, "it has been seen as a borderline that marks linguistic adulthood". Sentence coordination also presented significant differences showing higher scores in the higher grade, which is in line with findings by Ai and $\mathrm{Lu}$ (2013), Lu (2011), and Lorenzo and Rodríguez (2014).

Some interesting findings were observed when we compared performance according to group. In the bilingual group, there were significant ascending differences in the higher level in the following subordination and coordination scores: compound sentence ratio, complex sentence ratio, compound-complex sentence ratio, and coordinate clause ratio. Surprisingly differences on scores in dependent clause ratio were not statistically significant. Similarly, in the non-bilingual group, all coordination and subordination measures were significantly higher in fourth year writings with the exception of the proportion of dependent clauses and the proportion of complex-compound sentences.

As we can observe, results point to a significant increase in both clausal coordination and phrasal elaboration but no significant difference in subordination in both groups. We nevertheless observe a significant growth in the proportion of compound-complex sentences only in the bilingual fourth grade. It seems that the gap in written competence between both grades may be less wide in the bilingual context, and the syntactic superiority of the fourth year students in this group is manifested by the use (however limited) of compound-complex sentences (rarely used in the non-bilingual group), which are the most complex of all the types of sentences examined.

The lack of significant increase in subordination is in line with the results of the study by Bulté and Housen (2014), who found that by the end of their studies, their university learners produced more complex phrases and coordinated clauses but not more subordinated clauses. It is possible, as Bulté and Housen (2014:53) argue that progress in L2 writing beyond the lower intermediate stages of development may also involve syntactic complexification through increased use of clausal coordination and not of subordination. More research work is needed to examine this issue.

In order to have further evidence in favour of the bilingual programme approach we also compared bilingual third year students and non-bilingual fourth year students. We found that not only did the bilingual programme third graders outperform non-bilingual programme 
third graders, but the former even outscored non-bilingual fourth graders despite them being a year younger, in the general quality of the composition, and in all the measures of syntactic complexity, being this superiority significant in the measures of nominalisation, coordination, subordination and overall complexity. These results are in line with those of Navés, and Victori (2010) that indicate that the positive effects of bilingual education are evident even when the bilingual programme students are a year younger than the non-bilingual programme students are. It could then not be argued that CLIL students' outperformance were only attributable to greater exposure to the target language, but also to the methodology used in these programmes.

This study also showed a significant link between the complexity measures and the subjective rating. We found significant correlations between the overall rating of the compositions and almost all the complexity metrics in both groups. This finding suggested that the linguistic complexity measures selected quite exhaustively captured L2 writing quality or ability.

\section{Conclusion}

We have studied syntactic complexity in the writings of secondary education students and have examined the potential of complexity for describing L2 difference and improvement in different educational settings and across different proficiency levels using measures that gauge complexity at the sentential, the clausal, and the phrasal level of syntactic organisation. This has allowed us to get a wider picture of L2 writing development in these educational settings, since it has led to the identification of relevant areas of complexity at different given proficiency levels.

On the basis of the dataset analysed here, our analyses do indicate how the writing skill as captured by multiple complexity measures is consolidated in higher grades. However, it also suggests differences between the programme groups examined in some complex sentence types that calls for further research. Further studies are also needed to determine whether the lack of progress in subordination found in both groups is a significant trend in L2 writing development in the bilingual and the non-bilingual educational settings.

Before we conclude, it is important to acknowledge some limitations of the current study, which may be addressed in future research. This research has analysed two educational settings in terms of the complexity of their writings; the comparison between them seem to show the positive impact of bilingual programmes on secondary education learners' writing development in English, suggesting that bilingual settings, which involve integrating both content and language goals, seem to provide suitable contexts in which to develop written discourse. However, although we believe that the results obtained for both groups make a relevant valid contribution to the field, it is necessary to highlight the fact that students enrolled in bilingual programmes had more EFL exposure as compared to students in non-bilingual programmes. Therefore, future research works will have to be carried out including a pre-selection of participants in terms of their level of EFL exposure/proficiency in both instructional contexts. This will help us to confirm the results obtained in the present study. 


\section{RefERENCES}

Ai, H., and Lu, X. (2013). "A corpus-based comparison of syntactic complexity in NNS and NS university students writing", in A. Díaz-Negrillo, N. Ballier and P. Thompson (eds.), Automatic treatment and analysis of corpus data. Amsterdam: John Benjamins, 249-264.

Bulté, B., and Housen, A. (2015). "Conceptualizing and measuring short-term changes in L2 writing complexity", in Journal of Second Language Writing, 26, 42-65.

Gené-Gil, M. Juan-Garau, M., and Salazar-Noguera, J. (2015). "Development of EFL writing over three years in secondary education: CLIL and non-CLIL settings", in The Language Learning Journal, 43(3), 286-303.

Godfrey, L., and Treacy, C. (2014). "Change in French second language writing in study abroad and domestic contexts", in Foreign Language Annals, 47, 1, 48-65.

Heras, A., and Lasagabaster, D. (2015). "The impact of CLIL on affective factors and vocabulary learning", in Language Teaching Research, 19, 1, 70-88.

Ji-young Kim (2014). "Predicting L2 Writing Proficiency Using Linguistic Complexity Measures: A Corpus-Based Study", in English Teaching, 69(4), 27-51.

Knoch, U., Rouhshad, A., and Storch, N. (2014). "Does the writing of undergraduate ESL students develop after one year of study in an English-medium university?", in Assessing Writing, 21, 1-17.

Knoch, U., Rouhshad, A., Oon, S. P., and Storch, N. (2015). "What happens to ESL students' writing after three years of study at an English medium university?", in Journal of Second Language Writing, 28, 39-52.

Lasagabaster, D. (2008). "Foreign language Competence in content and language integrated courses", in The Open Applied Linguistics Journal, 1, 31-42.

Llinares, A., and Whittaker, R. (2006). "Linguistic analysis of secondary school students' oral and written production in CLIL contexts: social science in English", in Vienna English Working Papers 15, 3, 28-32.

Lorenzo, F., and Rodríguez, L. (2014). "Onset and expansion of L2 cognitive academic language proficiency in bilingual settings: CALP in CLIL", in System, 47, 64-72.

Mazgutova, D., and Kormos, K. (2015). "Syntactic and lexical development in an intensive E. A. P. programme", in Journal of Second Language Writing, 29, 3-15.

Navés, T., and Victori, M. (2010). "CLIL in Catalonia: an overview of research studies", in D. Lasagabaster, D. and Y. Ruiz de Zarobe (eds.), CLIL in Spain: Implementation, Results and Teacher Training. Newcastle: Cambridge Publishing, 30-54.

Norris, J. M., and Ortega, L. (2009). "Measurement for understanding: An organic approach to investigating complexity, accuracy, and fluency in SLA", in Applied Linguistics, 30, 555-578.

Roquet, H. 2011. A study of the acquisition of English as a Foreign Language: integrating content and language in mainstream education in Barcelona. Unpublished PhD diss., Universitat Pompeu Fabra.

Taguchi, N., Crawford, B., and Wetzel, D. (2013). "What linguistic features are indicative of writing quality?", in TESOL Quarterly, 47, 420-430.

Verspoor, M., and Sauter, K. (2000). English sentence analysis: An introductory course. Amsterdam: John Benjamins. 
Wolfe-Quintero, K., Inagaki, S., and Kim, H.-Y. (1998). Second language development in writing: Measures of fluency, accuracy, and complexity. Honolulu: University of Hawaii, Second Language Teaching \& Curriculum Center.

Yang, W., and Sun, Y. (2015). "Dynamic development of CAF in multilingual learners' L1, L2 and L3 writing", in Theory and Practice in Language Studies, 5(2), 298-308.

Yang, W., Lu, X., and Weigle, S. (2015). "Different topics, different discourse: Relationships among writing topic, measures of syntactic complexity, and judgments of writing quality", in Journal of Second Language Writing, 28, 53-67. 